\title{
Male-Specific Volatiles Released by the Big Avocado Seed Weevil Heilipus lauri Boheman (Coleoptera: Curculionidae)
}

\author{
Alicia A. Romero-Frías, ${ }^{\circledR *, a}$ Diana C. Sinuco ${ }^{b}$ and José Maurício S. Bento ${ }^{c}$ \\ ${ }^{a}$ Grupo de Investigación en Ciencias Biológicas y Químicas, Facultad de Ciencias, \\ Universidad Antonio Nariño, Sede-Bogotá, 111321 Bogotá, Colombia \\ ${ }^{b}$ Grupo de Bioprospección de Compuestos Volátiles, Departamento de Química, \\ Universidad Nacional de Colombia, Sede-Bogotá, 111321 Bogotá, Colombia \\ 'Departamento de Entomologia e Acarologia, Escola Superior de Agricultura “Luiz de Queiroz", \\ Universidade de São Paulo, 13418-900 Piracicaba-SP, Brazil
}

\begin{abstract}
The big avocado seed weevil, Heilipus lauri Boheman (Coleoptera: Curculionidae), is one of the most significant pests of avocado in Colombia and other countries, such as Mexico. The volatile compounds produced by males and females were collected by headspace (HS)-solid phase microextraction (SPME) and dynamic headspace collection (DHS) on a sorbent. Comparative analysis of these volatile compounds was performed using gas chromatography (GC)-flame ionization detector (FID) and GC coupled with mass spectrometry (MS). Four male-specific compounds were identified as grandisol, papayanol, papayanal and grandisal in a ratio of 94.8:3.0:1.8:0.4. Our results may help in integrated pest management by using these semiochemicals for trapping and controlling population of this species.
\end{abstract}

Keywords: grandisol, Molytinae, pheromone

\section{Introduction}

Avocado trees are attacked by many species of phytophagous insects, including the stalk-, fruit-, and branch-boring curculionids of the genus Heilipus. ${ }^{1}$ The big avocado seed weevil, Heilipus lauri Boheman (Coleoptera: Curculionidae), is an important quarantine pest, reported in Colombia ${ }^{2,3}$ and Mexico. ${ }^{4}$ The biology of this pest is closely linked with the phenology of avocado trees. Adults of $H$. lauri are diurnal, active from 9:00 a.m. to 7:00 p.m., and their presence is noticeable during the avocado fruiting period when they drill holes and feed on seeds, fruits and other reproductive parts of the plants. For this reason, the presence of this species requires control measures, for example when the fruit is intended for export. ${ }^{1,3}$

Because of environmental and regulatory concerns, research on developing alternative control strategies is mandatory. Since there has been growing attention to understanding chemical communication, the identification of the pheromone of $\mathrm{H}$. lauri could be useful for the implementation of a pest-management program, as for other

*e-mail: aaromerof@uan.edu.co species of weevils. The use of pheromones is a safe and sustainable alternative in control programs for agricultural insect pests, using monitoring, mass trapping or mating disruption..$^{5,6}$ The advantages of using pheromones for monitoring or controlling pests include low or even null environmental-pollution impact, lower costs, specificity, ease of use, and high sensitivity. ${ }^{7}$

Male-produced aggregation pheromones are known for many weevil species, which commonly use them for both host-finding and mating. ${ }^{8,9}$ Aggregation pheromones have been reported for weevils of subfamily Molytinae, including Pissodes spp. ${ }^{10}$ Conotrachelus nenuphar, ${ }^{11}$ Sternechus subsignatus, ${ }^{12,13}$ Conotrachelus psidii, ${ }^{14,15}$ Conotrachelus humeropictus ${ }^{16}$ and Acrotomopus atropunctellus. ${ }^{17}$

Currently, cultural and chemical control strategies are used for the big avocado seed weevil H. lauri. However, sprayed insecticides are ineffective because they cannot kill the larvae inside the fruits. ${ }^{1-3}$ Traps have not yet been developed for this pest, due to lack of information about its pheromones. Semiochemical-based monitoring and mass trapping are potential strategies to control $H$. lauri. This study aimed to provide evidence for semiochemical 
mediation of the chemical communication between conspecific individuals in $\mathrm{H}$. lauri, and to identify candidate structures of the corresponding compounds as a basis for further development of an integrated pest-management program for the big avocado seed weevil.

\section{Experimental}

Insects

Adults of $H$. lauri were collected in April through June 2017 from different managed avocado orchards in Herveo (Tolima, Colombia), by the beating-tray method after shaking branches of avocado trees. In the laboratory, the adults were separated by sex and maintained in plastic boxes with leaves and pieces of green avocado fruits as food, in a climate-controlled room at $20 \pm 2{ }^{\circ} \mathrm{C}, 80 \pm 10 \%$ relative humidity, and $12 \mathrm{~h}$ light: $12 \mathrm{~h}$ dark photoperiod. ${ }^{3}$

\section{Collection of volatiles from male and female insects}

Volatile compounds released by $H$. lauri adults were collected in the laboratory by using headspace (HS)-solid phase microextraction (SPME) and dynamic headspace (DHS) collection, with polymer-based sorbents. For HS-SPME, the weevils (males or females, separately) were starved in a room free from odorants and placed in $200-\mathrm{mL}$ glass flasks. The volatile compounds were collected on a divinylbenzene (DVB)/carboxen (CAR)/ polydimethylsiloxane (PDMS) fiber $(50 / 30 \mu \mathrm{m}$ thickness, Supelco, Bellefonte, PA, USA) for $24 \mathrm{~h}$. The analyses were done in triplicate, with different insects each time (1 male or 1 female), immediately after the insects arrived at the laboratory. Analysis of background volatiles was performed with the SPME fiber in the flask without insects. For DHS collection, groups of 3 males and 3 females were held in individual all-glass aeration chambers $(33 \mathrm{~cm}$ high $\times 4 \mathrm{~cm}$ outlet diameter) with two leaves and fresh unripe avocado fruits (4-6 g each) at $18-20{ }^{\circ} \mathrm{C}$. The food was available for the insects in the aeration chambers during the entire aeration period. The released volatiles were collected continuously for 4 days (minimum time required to detect volatile compounds), and trapped in glass columns $(10 \mathrm{~cm}$ high $\times 0.5 \mathrm{~cm}$ i.d.) packed with $0.5 \mathrm{~g}$ of $\mathrm{ORBO}$ 32 (small activated coconut charcoal (20/40), 100/50 mg, $6 \mathrm{~mm}$ o.d. $\times 75 \mathrm{~mm}$ length, Supelco). Before use, the packed columns were washed with hexane high performance liquid chromatography (HPLC) grade (Merck, Darmstadt, Germany). The charcoal-filtered humidified air was pushed through the aeration system $\left(1.0 \mathrm{~L} \mathrm{~min}^{-1}\right.$ per chamber). The adsorbed volatile compounds were eluted with $300 \mu \mathrm{L}$ of hexane HPLC grade (Merck). The extracts were concentrated to about $50 \mu \mathrm{L}$ under a nitrogen stream in a clean conical-bottom vial. Blank experiments were performed under the same conditions, in the presence of leaves and fresh unripe avocado fruits but without insects.

To select the materials that retained the largest number of volatile components, in the preliminary assays the volatiles were extracted with four commercially available fibers (PDMS, $100 \mu \mathrm{m}$; PDMS/DVB, $65 \mu \mathrm{m}$; CAR/PDMS, $75 \mu \mathrm{m}$; and PDMS/DVB/CAR, 50/30 $\mu \mathrm{m}$ ) and different adsorbents (DVB polymer (HayeSep D, Merck KGaA, Darmstadt, Germany), and 4-ethylstyrene-DVB and ORBO 32 (Porapak Q, Merck KGaA, Darmstadt, Germany)) under the same conditions as the fiber and adsorbent selected for the HS-SPME and DHS collection, respectively.

\section{Analytical procedures}

For gas chromatography (GC) and coupled GC-mass spectrometry (MS) analyses, $1 \mu \mathrm{L}$ of the DHS extracts was injected in a 7820A GC system (Agilent Technologies, Santa Clara, USA) and HP 6890 Series GC coupled to an HP 7973 mass selective detector (Hewlett Packard, Palo Alto, USA), respectively, while the volatile compounds collected by HS-SPME from insects were desorbed in both gas chromatograph systems (GC-flame ionization detector (FID) and GC-MS). Desorption time was set at $5 \mathrm{~min}$. Two capillary columns, ZB-5 and DB-WAX (each $30 \mathrm{~m} \times 0.32 \mathrm{~mm}$ i.d., $0.25 \mu \mathrm{m}$ film thickness; Phenomenex, Torrance, USA, and Agilent J\&W Scientific, Chromatography-Handel Müller, Fridolfing, Germany, respectively) were used. The column oven was programmed from $50^{\circ} \mathrm{C}$ for $1 \mathrm{~min}$, then raised to $250^{\circ} \mathrm{C}$ at $7{ }^{\circ} \mathrm{C} \mathrm{min}^{-1}$ and maintained at that temperature for $10 \mathrm{~min}$. The injector temperature was fixed at $250^{\circ} \mathrm{C}$ for both columns, using helium as carrier gas at $1.5 \mathrm{~mL} \mathrm{~min}{ }^{-1}$. The injection port was operated in splitless mode.

Linear retention indices (LRI) were calculated according to the Kovats method, using a mixture of $n$-alkanes as external references. ${ }^{18}$ Mass spectral identification was completed via comparison with either authentic reference standards or spectra from commercial mass spectral databases..$^{19} \mathrm{MS}$ data in the electron ionization (EI) mode were recorded in a mass range of 30-650 u, with electron energy of $70 \mathrm{eV}$, and processed by HP Chemstation software.

\section{Reference compounds}

Pure reference standards of $\beta$-pinene, myrcene, eucalyptol, limonene, ocimene, $\beta$-caryophyllene, $\alpha$-humulene and $n$-alkane mix $\left(\mathrm{C}_{8}-\mathrm{C}_{40}\right)$ were purchased from Sigma-Aldrich (Taufkirchen, Germany). Pure 
$((1 R, 2 S, 6 R)-2,6$-dimethyl-3-oxabicyclo[4.2.0] octan-2-yl)methanol $((1 R, 2 S, 6 R)$-papayanol) and $(1 R, 2 S, 6 R)$-2,6-dimethyl-3-oxabicyclo[4.2.0]octane2 -carbaldehyde $((1 R, 2 S, 6 R)$-papayanal) were kindly provided by Dr Yasuhiro Murata from Fuji-Flavor Co. (Tokyo, Japan $)^{15}$ and $(1 R, 2 S)$-cis-1-isopropenyl1-methylcyclobutaneethanal $((1 R, 2 S)$-grandisal $)$ was kindly supplied by Dr Paulo Zarbin from Universidade Federal do Paraná (Curitiba, Brazil). ${ }^{20}(1 R, 2 S)$-Grandisol $(94 \%$ enantiomeric excess, $[\alpha]_{\mathrm{D}}^{25}+15.8^{\circ}(\mathrm{c}=1.01, n$-hexane $\left.)\right)$ was obtained by recrystallization from $(+)-2-[(1 R, 2 S)-1$-methyl2-(prop-1-en-2-yl)cyclobutyl]ethanol (grandisol; Grandlure I, Bedoukian Research Inc., Danbury, CT, USA).

\section{Results and Discussion}

Two methods (HS-SPME and DHS) for the volatile compounds released by $H$. lauri were evaluated by GC-MS and their relative concentrations determined by the area percentage in GC analysis (Table 1). Taking into account that the fiber composition determines the selectivity of the analysis, four commercially available fibers were tested as part of the preliminary assays (PDMS, $100 \mu \mathrm{m}$; PDMS/DVB, $65 \mu \mathrm{m}$; CAR/PDMS, $75 \mu \mathrm{m}$; and $\mathrm{PDMS} / \mathrm{DVB} / \mathrm{CAR}, 50 / 30 \mu \mathrm{m})$. The last one was chosen because it retained the largest number of volatile components. DHS was used to obtain volatile extracts from the insects. During preliminary experiments, ORBO 32 (charcoal adsorbent tubes) extracted volatile organic compounds (VOCs) better than HayeSep D (DVB) polymer and Porapak Q (4-ethylstyrene-DVB).
The volatile profiles collected with HS-SPME and DHS extracts were the same (Table 1). In both cases, four male-specific compounds and seven plant compounds were detected. $\beta$-Pinene, myrcene, eucalyptol, limonene, ocimene, $\beta$-caryophyllene and $\alpha$-humulene were identified from males and females of big avocado seed weevils, by comparison of their retention indexes and mass spectra with those of corresponding commercially available standards.

HS-SPME is a solvent-free, simple, inexpensive, rapid, and versatile method for the extraction of volatile compounds. This technique has been applied successfully in a wide range of analytical applications involving sampling of living organisms. ${ }^{21}$ In our results, the sensitivity and precision provided by HS-SPME were comparable to the DHS technique traditionally employed for the analysis of insect samples.

Using both techniques without (HS-SPME) and in the presence of food (DHS), four male-specific compounds were identified in a ratio of 94.8:3.0:1.8:0.4 through GC-MS analyses: grandisol (a), papayanol (b), papayanal (c), and grandisal (d), respectively (Figure 1).

The plant compounds $\beta$-pinene, myrcene, eucalyptol, limonene and $\beta$-caryophyllene detected in this study were present in avocado leaves, using the same fiber. ${ }^{22}$ The interaction between phytophagous insects and their hosts is mediated by VOCs that are synthesized during plant metabolism and released into the environment. Thus, VOCs often play a role as sensory cues that define host specificity (food or oviposition site). Pheromone production is often associated with feeding; it is experimentally difficult to distinguish between host compounds that are released by

Table 1. Volatile compounds released by male and female avocado weevils, Heilipus lauri

\begin{tabular}{|c|c|c|c|c|c|c|c|c|}
\hline \multirow{3}{*}{ No. } & \multirow{3}{*}{ Compound } & \multirow{3}{*}{$\mathrm{ID}^{\mathrm{a}}$} & \multicolumn{2}{|c|}{$\mathrm{RI}^{\mathrm{b}}$} & \multicolumn{4}{|c|}{ Volatile compounds released by $H$. lauri ${ }^{\mathrm{c}}$ (source and method) } \\
\hline & & & \multirow{2}{*}{ ZB-5 } & \multirow{2}{*}{ DB-WAX } & \multicolumn{2}{|c|}{ Male } & \multicolumn{2}{|c|}{ Female } \\
\hline & & & & & $\mathrm{HS}^{\mathrm{SPME}} \mathrm{d}^{\mathrm{d}}$ & DHS $^{\mathrm{e}}$ & HS-SPMEd & DHS $^{\mathrm{e}}$ \\
\hline 1 & $\beta$-pinene & std & 994 & 1107 & + & + & + & + \\
\hline 2 & myrcene & std & 995 & 1170 & + & + & + & + \\
\hline 3 & eucalyptol & std & 1030 & 1220 & + & + & + & + \\
\hline 4 & limonene & std & 1034 & 1212 & ++ & ++ & ++ & ++ \\
\hline 5 & ocimene & std & 1045 & - & + & + & + & + \\
\hline 6 & grandisal & std & 1127 & - & + & + & - & - \\
\hline 7 & papayanal & std & 1184 & 1713 & + & + & - & - \\
\hline 8 & grandisol & std & 1214 & 1792 & ++++ & ++++ & - & - \\
\hline 9 & papayanol & std & 1268 & 1856 & + & + & - & - \\
\hline 10 & $\beta$-caryophyllene & std & 1433 & 1594 & + & + & + & + \\
\hline 11 & $\alpha$-humulene & std & 1468 & 1656 & + & + & + & + \\
\hline
\end{tabular}

a Source of compound identification: standard (std), retention index and mass spectra comparison with reference compound; ${ }^{\mathrm{b}}$ retention index; ${ }^{\mathrm{c}} \mathrm{Volatile}$

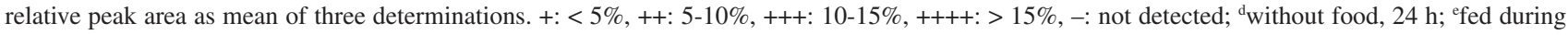
aeration; ZB-5 and DB-WAX: capillary columns; HS-SPME: headspace-solid phase microextraction; DHS: dynamic headspace. 
masticated food or feces, and those that are sequestered by the weevil and released later. ${ }^{23,24}$

Chromatographic profiles of volatiles of male and female of $H$. lauri revealed the presence of four malespecific compounds. Since the available amounts of natural products were too small for nuclear magnetic resonance (NMR) studies, structure assignments were based on mass spectra and comparison of GC retention times with those of synthetic standards.

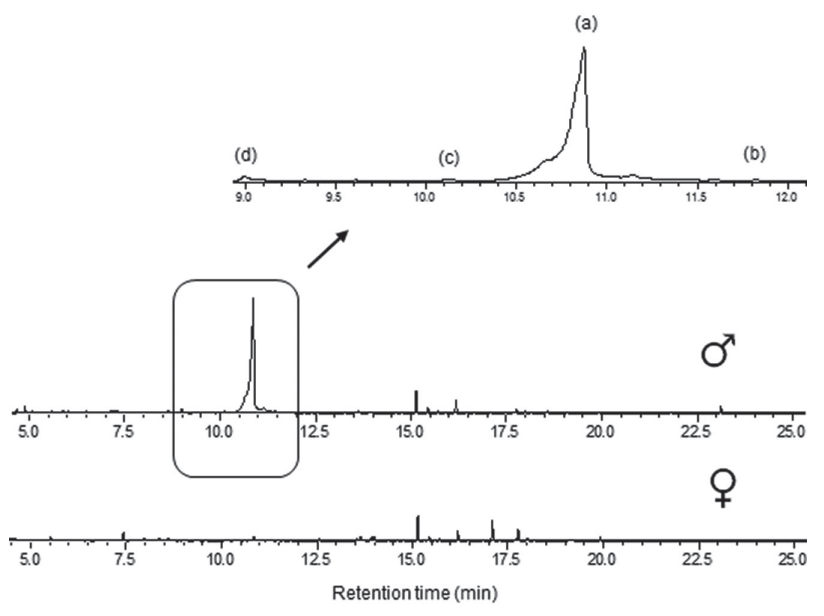

Figure 1. Gas chromatogram (FID) of volatile headspace extracts obtained from aeration of males and females of Heilipus lauri, showing male-specific compounds (a)-(d). Conditions: Agilent 7820A GC system; capillary column ZB-5 (30 $\mathrm{m} \times 0.32 \mathrm{~mm}$ i.d., $0.25 \mu \mathrm{m}$ film thickness); splitless; $1 \mathrm{~min}$ at $50^{\circ} \mathrm{C}$, then ramped to $250^{\circ} \mathrm{C}$ at $7^{\circ} \mathrm{C} \mathrm{min}{ }^{-1}$ and $10 \mathrm{~min}$ at $250{ }^{\circ} \mathrm{C}$.

The mass spectrum of the major component, compound a (Figure 2a), showed a molecular ion at $\mathrm{m} / \mathrm{z} 154$ and a characteristic base peak at $m / z$ 68, suggesting that the compound was grandisol, which was confirmed by comparison with a purified commercial standard. Comparison of retention times [Kovats index (KI) 1214/ZB-5 and KI 1792/DB-WAX] of the natural product with the synthetic $(1 R, 2 S)$-stereoisomer obtained by recrystallization, revealed the latter to be grandisol. This compound has been found in several other curculionid species. ${ }^{10,12,13,16}$

For compound d, the mass spectrum showed a molecular ion at $\mathrm{m} / \mathrm{z}, 152$ and, similar to grandisol, a base peak at $m / z 68$ (Figure 2d). Investigations by GC-MS spectrometry provided analytical data and fragmentation patterns that strongly suggested that compound d was grandisal. Comparison with the pure synthetic compound confirmed the grandisal structure.

The structure of the male-specific compound $\mathbf{b}$ was assigned based on MS data and also by comparison with an authentic standard. The mass spectrum (Figure 2b) of the target compound [KI 1268/ZB-5] showed the following significant signals $m / z(\%): 139(100), 111(27)$, 81(30), 69(74), 43(50). The fragmentation pattern strongly resembled that of papayanol, a pheromone component of the papaya weevil, Pseudopiazurus obesus, ${ }^{20,25}$ and the guava weevil, Conotrachelus psidii. ${ }^{14}$ The identification of the compound was confirmed after co-injection with an authentic standard of $(1 R, 2 S, 6 R)$-papayanol. The stereochemistry of this compound was not confirmed in this study, but we suggested that it might be identical to that reported for the papaya and guava weevils.

The minor male-specific compound $\mathbf{c}$ showed a fragmentation pattern (Figure 2c) very similar to that of papayanol. The structure for compound $\mathbf{c}$ was suggested to be papayanal, an analog aldehyde derived from papayanol. The signals at $m / z 139[\mathrm{M}-29]^{+}$and $m / z 111[\mathrm{M}-57]^{+}$

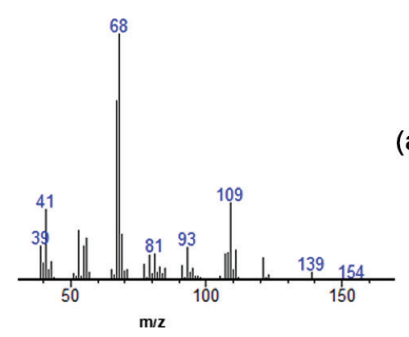

(a)

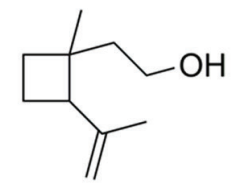

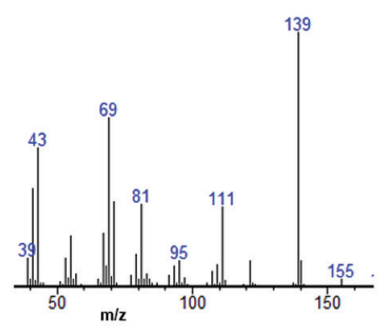

(b)

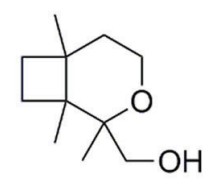

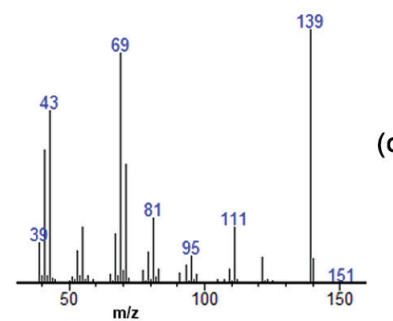

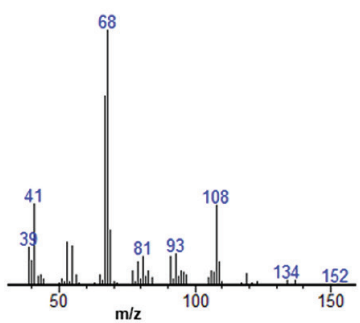

(c)<smiles>CC12CCCC1C(C)(C=O)OCC2</smiles>

(d)<smiles>C=C(C)C1CCC1(C)CC=O</smiles>

Figure 2. MS and chemical structures of compounds: (a) grandisol; (b) papayanol; (c) papayanal and (d) grandisal. 
in the EI mass spectrum corresponded to the loss of formyl and $\mathrm{CH}_{2}=\mathrm{CH}-\mathrm{CHO}^{+}$groups from the molecular ion, respectively. A pure synthetic standard confirmed the chemical structure of this compound.

Our results were obtained with Colombian insects collected in different periods of the year. The major compound was identified as grandisol, by GC-MS co-injection with a pure enantiomeric sample, allowing us to suggest this compound as a candidate aggregation pheromone of $H$. lauri. The presence of grandisal, papayanol and papayanal is supported by biogenetic reasons. Both grandisol and grandisal are well-known components of weevil pheromones. Grandisol produced by $H$. lauri has been found in Anthonomus grandis, ${ }^{26}$ Pissodes spp., ${ }^{27}$ Pseudopiazurus obesus ${ }^{20,25}$ and Conotrachelus humeropictus. ${ }^{16}$ The enantioselective biosynthesis of grandisol and grandisal appears to be significant for the behavior and interspecific discrimination of certain species of weevils, ${ }^{28}$ the insects utilize chirality to enrich and diversify their communication systems. ${ }^{29}$ However, Mori ${ }^{29}$ reported that the opposite enantiomer of the $(1 R, 2 S)$-grandisol does not inhibit the response to the active stereoisomer, for example, in cotton boll weevil, A. grandis, or in pecan weevil, Curculio caryae and also described that in Pissodes strobi or P. nemorensis antennae detected both enantiomers of grandisal. Pheromones of these species can be used as their racemates in practical applications.

As a common structural feature, grandisol and related compounds identified in $H$. lauri have a terpenoid skeleton. ${ }^{30}$ This similarity suggests biogenesis from host-plant terpenes, although no biosynthesis study has confirmed this. The production and release of insect pheromones are governed by a variety of environmental factors and physiological mechanisms. Furthermore, the amounts of pheromones that an insect releases are extremely low, ranging from a few ng to $\mu \mathrm{g}$ per unit of time, depending on the species. ${ }^{31}$

Male-specific pheromone components have been identified in various curculionid species of the subfamily Molytinae and have been described as a part of their systems of chemical communication, for monitoring populations. The identities of all the $H$. lauri pheromone candidates (Figure 3) were confirmed by the co-injection of authentic standards. The male-specific compounds extracted from $H$. lauri are components of aggregation pheromones in several other species of the family Curculionidae, such as A. grandis,,${ }^{26}$ P. obesus, ${ }^{20,25}$ Pissodes spp., ${ }^{10,27}$ C. psidii ${ }^{14,15}$ and C. humeropictus. ${ }^{16}$

In other curculionid species, the cotton weevil A. grandis, ${ }^{26}$ papaya weevil $P$. obesu ${ }^{20,25}$ and guava weevil
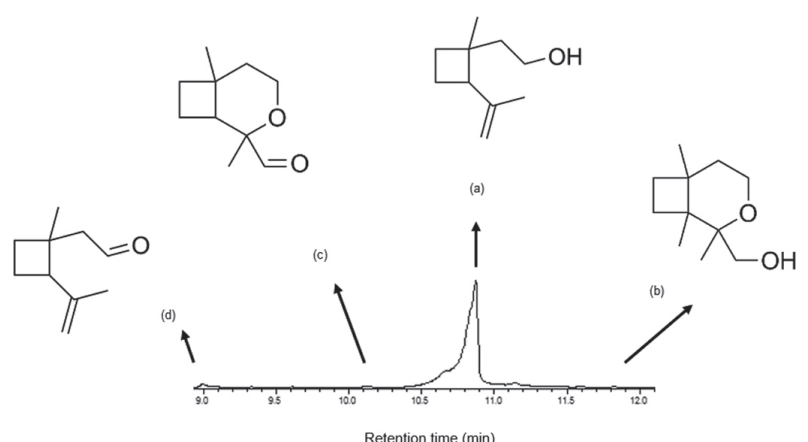

Figure 3. Chemical structures of the four male-specific compounds (a)-(d) produced by Heilipus lauri.

C. psidii, ${ }^{14,15}$ a mixture of alcohol and aldehyde was identified as aggregation pheromones.

\section{Conclusions}

Our results demonstrated that males of $H$. lauri produced four sex-specific volatile compounds and suggested that communication in $H$. lauri is mediated by semiochemicals, more specifically by insect-produced aggregation pheromones. The male-specific compounds grandisol, grandisal, papayanol and papayanal are the most important pheromone candidates in the species. This is the first time that the compounds identified are suggested to have a role as aggregation-pheromone components in avocado weevil. However, further experimentation is needed to confirm this supposition.

Laboratory and field studies are underway to evaluate the biological activity of the complete four-component blend of $H$. lauri. These results contribute both to the understanding of the chemical ecology of H. lauri and to its potential to improve the accuracy of integrated pest management (IPM) estimates.

\section{Acknowledgments}

The authors are grateful to Luis Sigifredo Caicedo, Manuel Benavides, Jairo Ochoa and the Asociación de Productores de Aguacate, Frutas y Hortalizas (ASFRUHER; Herveo, Tolima, Colombia) for their valuable cooperation during the collection of weevils in the countryside of Tolima, Colombia. They also thank Dr Yasuhiro Murata and Dr Paulo Zarbin for the synthetic standards. This research was supported by grants from the Vicerrectoría de Ciencia, Tecnología e Innovación, Universidad Antonio Nariño (2016201); Dirección Nacional de Investigación (DIB), Universidad Nacional de Colombia-Sede Bogotá; and the National Institute of Science and Technology (Semiochemicals in Agriculture; FAPESP and CNPq grants No. 2014/50871-0 and No. 465511/2014-7, respectively). 


\section{References}

1. Castañeda-Vildózola, A.; Palacio-Torres, R.; Sánchez-Pale, J.; Franco-Mora, O.; Valdez-Carrasco, J.; Equihua-Martínez, A.; Coleopt. Bull. 2017, 71, 361.

2. Caicedo, R.; Devia, E.; Bacca, T.; Carabalí, A.; Corpoica Cienc. Tecnol. Agropecu. 2010, 11, 129.

3. Díaz, V.; Caicedo, A. M.; Carabalí, A.; Acta Zool. Mex. 2017, 33,231 .

4. Castañeda-Vildózola, A.; González-Hernández, H.; Equihua, A.; Valdez-Carrasco, J.; Peña, J.; Cazado, L.; Franco-Mora, O.; Fla. Entomol. 2016, 99, 822.

5. Witzgall, P.; Kirsch, P.; Cork, A.; J. Chem. Ecol. 2010, 36, 80.

6. Trematerra, P.; J. Pest Sci. 2012, 85, 285.

7. Pélozuelo, L.; Frérot, B.; J. Econ. Entomol. 2007, 100, 1797.

8. Bartelt, R. J. In Pheromones of Non-Lepidopteran Insects Associated with Agricultural Plants; Hardie, J.; Minks, A. K., eds.; CABI Publishing: Wallingford, 1999, ch. 5.

9. Tewari, S.; Leskey, T. C.; Nielsen, A. L.; Piñero, J. C.; Rodríguez-Saona, C. R. In Integrated Pest Management: Current Concepts and Ecological Perspectives, $1^{\text {st }}$ ed.; Abrol, D. P., ed.; Academic Press: San Diego, 2014, ch. 9.

10. Booth, D.; Phillips, T.; Claesson, A.; Silverstein, R.; Lanier, G.; West, J.; J. Chem. Ecol. 1983, 9, 1.

11. Eller, F. J.; Bartelt, R.; J. Nat. Prod. 1996, 59, 451.

12. Ambrogi, B. C.; Zarbin, P. H. G.; J. Appl. Entomol. 2008, 132, 54.

13. Ambrogi, B. C.; Palacio-Cortés, A. M.; Zarbin, P. H. G.; J. Chem. Ecol. 2012, 38, 272.

14. Palacio-Cortés, A.; Valente, F.; Saad, E.; Tröger, A.; Francke, W.; Zarbin, P. H. G.; J. Braz. Chem. Soc. 2015, 26, 784.

15. Romero-Frías, A.; Murata, Y.; Bento, J. M. S.; Osorio, C.; Biosci., Biotechnol., Biochem. 2016, 80, 848.

16. Szczerbowski, D.; Torrens, G.; Rodrigues, M.; Trevisan, O.; Gomes, S.; Tröger, A.; Mori, K.; Francke, W.; Zarbin, P. H. G.; Tetrahedron Lett. 2016, 57, 2842.
17. Rodríguez, S. A.; Pérez, M. L. P.; Nazareno, M. A.; Bull. Entomol. Res. 2016, 106, 494.

18. Ettre, L.; Billeb, K.; J. Chromatogr. 1967, 30, 1.

19. McLafferty, F. W.; Wiley Registry of Mass Spectral Data, with NIST 2008, $9^{\text {th }}$ ed.; Wiley: Hoboken, 2010.

20. Zarbin, P. H. G.; Moreira, M. A. B.; Haftmann, J.; Francke, W.; Oliveira, A. R. M.; J. Braz. Chem. Soc. 2007, 18, 1048.

21. Augusto, F.; Valente, A.; TrAC, Trends Anal. Chem. 2002, 21, 428.

22. López, M.; Guzmán, G.; Dorantes, A.; J. Chromatogr. A. 2004, 1036, 87.

23. Vanderwel, D.; Oehschlager, A. In Pheromone Biochemistry; Prestwich, G. D.; Blomquist, G. J., eds.; Academic Press: Orlando, 1987, ch. 10.

24. Blomquist, G.; Figueroa-Teran, R.; Aw, M.; Song, M.; Gorzalski, A.; Abbott, N.; Chang, E.; Tittiger, C.; Insect Biochem. Mol. Biol. 2010, 40, 699.

25. Zarbin, P. H. G.; Moreira, M. A. B.; Haftmann, J.; Tröger, A.; Franke, S.; Kopf, J.; Mori, K.; Francke, W.; Org. Lett. 2010, 12, 2447.

26. Tumlinson, J.; Hardee, D.; Gueldner, R.; Thompson, A.; Hedin, A.; Minyard, A.; Science 1969, 166, 1010.

27. Phillips, T.; West, J.; Foltz, J.; Silverstein, R.; Lanier, G.; J. Chem. Ecol. 1984. 10, 1417.

28. Tillman, J.; Seybold, S.; Jurenka, R.; Blomquist, G.; Insect Biochem. Mol. Biol. 1999, 29, 481.

29. Mori, K.; Bioorg. Med. Chem. 2007, 15, 7505.

30. Ambrogi, B. G.; Vidal, D. M.; Zarbin, P. H. G.; Quim. Nova 2009, 32, 2151.

31. Piñero, J.; Ruíz-Montiel, D. In Temas Selectos en Ecología Química de Insectos; Rojas-León, J.; Malo-Rivera, E. A., eds.; El Colegio de la Frontera Sur: Tapachula, 2012, p. 361.

Submitted: April 30, 2018 Published online: August 28, 2018 